\title{
Relation between Lymphopenia and Internal Organ Involvement in Systemic Lupus Erythematosus Patients
}

\author{
Amal S. Abd El Hamed ${ }^{1}$, Ahmed R. Radwan*1, Mohammed A. Ismail', Abd Elhady Ragab², \\ Ashraf A. Abdelwahab ${ }^{3}$, Ibtesam K. Ali ${ }^{1}$ \\ Departments of ${ }^{1}$ Physical Medicine, Rheumatology \& Rehabilitation, ${ }^{2}$ Clinical Pathology and ${ }^{3}$ Dermatology, \\ Venereology \& Andrology, Faculty of Medicine, Sohag University, Egypt \\ *Corresponding author: Ahmed R. Radwan, Mobile: (+20)1092914019, Email: ahmed_radwan@med.sohag.edu.eg
}

\begin{abstract}
Background: Systemic lupus erythematosus (SLE) is an autoimmune disease, characterized by autoantibody production and immunocomplex formation, leading to widespread inflammatory damage involving multi-organ systems. Lymphopenia is a common laboratory involvement seen in patients with SLE and the mechanism of it is still unclear.

Objectives: The aim of the current study was to investigate the relation between lymphopenia and clinical manifestations, laboratory findings, and disease activity in systemic lupus erythematosus (SLE) patients.

Patients and Methods: It was a cross sectional study; with a total of 60 patients with SLE recruited from the Rheumatology and Rehabilitation outpatient clinic at Sohag University Hospital. Demographic data, personal history, detailed history of general health condition and chronic or current diseases were reported. All the participants were subjected to detection of erythrocyte sedimentation rate, liver function tests, renal function tests, complete blood count (CBC), renal biopsy, protein/creatinine ratio and/or $24 \mathrm{hr}$ protein in urine, urine analysis, ANA profile, and Complement 3 and 4.

Results: Two thirds of the study population had normal lymphocytic count, and one third had lymphopenia. Lymphopenia group showed significantly more hypochromic anemia with significant lower hemoglobin level and lower MCV. The mean creatinine level was significantly higher among lymphopenic cases. Lymphopenic cases had higher proteinuria.
\end{abstract}

Conclusions: It could be concluded that lymphopenia in patients with SLE may be used as indicator of renal involvement in these patients.

Keywords: Systemic lupus erythematosus, Lymphopenia, Renal involvement.

\section{INTRODUCTION}

Systemic lupus erythematosus (SLE) is an autoimmune disease, which is characterized by excess autoantibody production and immunocomplex formation, leading to widespread inflammatory damage involving multi-organ systems. It may affect any organ and produce a broad spectrum of clinical manifestations (1). Lymphopenia is a common laboratory involvement seen in patients with SLE and the mechanism of it is still unclear ${ }^{(2)}$.

The clinical usefulness of lymphopenia has been limited mainly to aid in lupus diagnosis because lymphopenia is one of the hematologic criteria according to the American College of Rheumatology (ACR). Lymphopenia was found in the majority of SLE patients (over 60\%) on initial diagnosis and this rises to over $90 \%$ during the disease course of SLE ${ }^{(3)}$.

Lymphopenia was seen to be correlated with disease activity in adults with SLE. However, it may be caused by multi-factors other than SLE itself ${ }^{(4)}$.

Medications including corticosteroids, cytotoxic agents (e.g. cyclophosphamide) and many infections may contribute to the reduction in lymphocyte count ${ }^{(5)}$. Some studies have shown lymphopenia to be associated with particular clinical manifestations of SLE, disease activity and organ damage ${ }^{(\mathbf{1}, \mathbf{6})}$.
The aim of this study was to investigate the relation between lymphopenia and clinical manifestations, laboratory findings, disease activity in SLE patients.

\section{PATIENTS AND METHODS}

This cross-sectional study included 60 patients classified as SLE according to either the 2012 SLICC criteria or the new 2019 ACR/EULAR SLE classification criteria. Patients were recruited from the Rheumatology and Rehabilitation outpatient clinic at Sohag University Hospital.

\section{Inclusion criteria:}

1- Patients diagnosed as SLE according to SLICC 2012 or ACR/EULAR 2017 classification criteria.

2- Age (18-60) years

3- Patient with disease duration more than 6 months

\section{Exclusion criteria:}

1- Other autoimmune disease including rheumatoid arthritis, scleroderma, mixed connective tissue disease and polymyositis.

2- Patients who had active infections, malignancies, hematologic diseases, hepatosplenic diseases. 
All patients were evaluated as follow:

1- Full history taking (demographic data and personal history, detailed history of general health condition and chronic or current diseases).

2- Full clinical examination including: General examination and vital signs, and complete rheumatological examination.

3- Routine investigations (erythrocyte sedimentation rate, liver function tests, renal function tests)

4- ANA by immunofluorescence.

5- ANA profile for the most common 19 autoantibodies by immunoblot.

6- All the participants were subjected to detection of: Complete Blood count (CBC), protein creatinine $(\mathrm{P} / \mathrm{C})$ ratio and/or $24 \mathrm{hr}$ protein in urine, urine analysis, complement 3,4 and renal biopsy.

\section{Ethical approval:}

An approval of the study was obtained from Sohag University Academic and Ethical Committee. Each participant was informed about the research objective and methods in detail and using simple language prior to being requested to provide written informed consent prior to participation in the research. This work has been carried out in accordance with The Code of Ethics of the World Medical Association (Declaration of Helsinki) for studies involving humans.

\section{Statistical analysis}

Statistical package for social sciences (IBMSPSS), version 25 IBM- Chicago, USA (August 2017) was used for statistical data analysis. Data expressed as mean, standard deviation (SD), number and percentage. Mean and standard deviation were used as descriptive value for quantitative data, while number and percentage were used to describe qualitative data. Student $\mathrm{t}$ test was used to compare the means between two groups, and Mann Whitney test was used instead of Student t test in case of non-parametric data. Pearson Chi square was used to compare percentages of qualitative data, and Fisher's Exact test was used for non-parametric data. $\mathrm{P}$ value $<0.05$ was considered significant.

\section{RESULTS}

The patients were classified according to presence of lymphopenia into two groups; non-lymphopenic group $(n=40,66.7)$, and lymphopenic $(n=20,33.3 \%)$. The mean age of the study population was around 3233 years, with no significant difference between the two groups. All of the cases were females. The mean disease duration of the study groups was $4 \pm 4.7$ years for cases with lymphopenia compared to $3.6 \pm 4$ years for those with normal lymphocytic count, with no significant difference.

Table (1): Demographic and basic clinical data of the study population

\begin{tabular}{lccc}
\multicolumn{1}{c}{ Group } & $\begin{array}{c}\text { Lymphopenia } \\
(\mathbf{N}=\mathbf{2 0})\end{array}$ & $\begin{array}{c}\text { No } \\
\text { Lymphopenia } \\
(\mathbf{N}=\mathbf{4 0})\end{array}$ & $\begin{array}{c}\mathbf{P} \\
\text { value }\end{array}$ \\
\hline $\begin{array}{l}\text { Mean age } \\
\text { (years) }\end{array}$ & $32.95 \pm 7.37$ & $32.10 \pm 10.19$ & 0.741 \\
$\begin{array}{l}\text { Disease } \\
\text { duration }\end{array}$ & $3.99 \pm 4.71$ & $3.59 \pm 3.97$ & 0.740 \\
\hline
\end{tabular}

There was non-significant difference between the two groups as regards azathioprine, cyclophosphamide and hydroxychloroquine therapy. However, cases with normal lymphocytic count received significantly higher doses of steroids compared to those with lymphopenia and only 3 cases needed mycophenolate mofetil treatment (Table 2).

Table (2): Comparison of drug history in the study groups

\begin{tabular}{|c|c|c|c|}
\hline & $\begin{array}{c}\text { Lympho- } \\
\text { penia } \\
\text { positive } \\
(n=20)\end{array}$ & $\begin{array}{l}\text { Lympho- } \\
\text { penia } \\
\text { negative } \\
(n=40)\end{array}$ & $\begin{array}{c}P \\
\text { value }\end{array}$ \\
\hline Azathioprine & $11(55 \%)$ & $25(62.5 \%)$ & 0.402 \\
\hline $\begin{array}{l}\text { Hydroxy- } \\
\text { chloroquine }\end{array}$ & $12(60 \%)$ & $26(65 \%)$ & 0.441 \\
\hline Steroids & $5(25 \%)$ & $26(65 \%)$ & 0.019* \\
\hline $\begin{array}{l}\text { Cyclo- } \\
\text { phosphamide }\end{array}$ & $8(40 \%)$ & $22(55 \%)$ & 0.419 \\
\hline $\begin{array}{l}\text { Myco- } \\
\text { phenolate } \\
\text { mofetil }\end{array}$ & $1(5 \%)$ & $2(5 \%)$ & 1.0 \\
\hline
\end{tabular}

$* \mathrm{P}$ value $<0.05$ was considered significant

Regarding ANA; the majority of cases had ANA titres between $1 / 80$ to $1 / 320$, with no significant difference between the two groups regarding ANA titre $(\mathrm{P}=0.818)$ (Figure 1). 


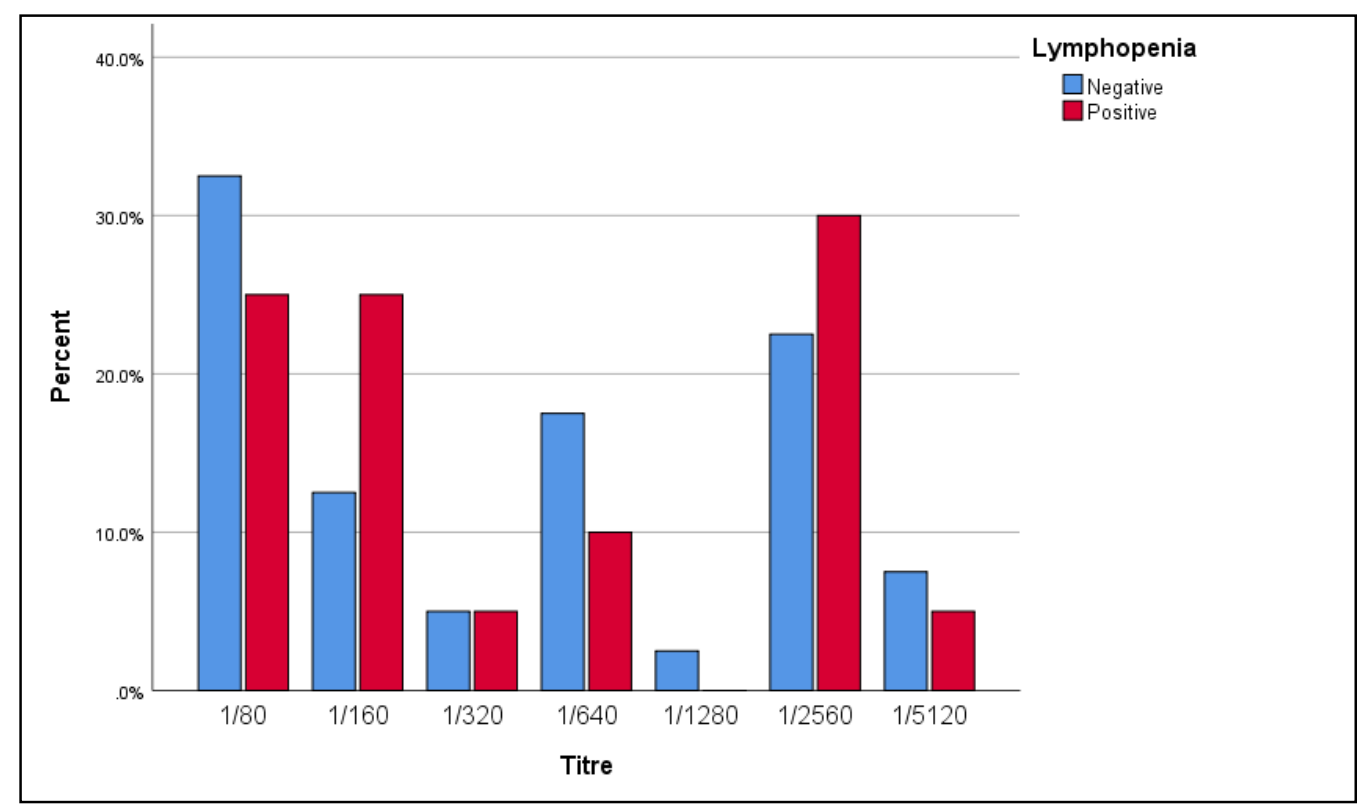

Figure (1): ANA titre in the study groups

Homogenous pattern was the dominant pattern among lymphopenic cases $(12,60 \%)$, followed by speckled pattern $(5,25 \%)$. In patients with normal lymphocytic count; the dominant pattern was the speckled one $(20,50 \%)$, followed by homogenous pattern $(14,35 \%)$. There was no significant difference between the two groups as regards ANA patterns $(\mathrm{P}=0.214)$.

The most common ANA antibodies were the anti dsDNA, anti-Smith, anti-nucleosome, anti Sm-RNB; followed by anti-Ro and Anti La. All these antibodies showed non-significant differences between the two groups (Table 3).

\section{Table (3): ANA profile in the study groups}

\begin{tabular}{lcccc} 
& \multicolumn{2}{c}{ Lymphopenia } & Chi square & P value \\
\cline { 2 - 3 } & \multicolumn{2}{c}{ Positive (n=20) } & Negative (n=40) & \\
\hline Anti ds- DNA & $10(50 \%)$ & $27(67.5 \%)$ & 1.727 & 0.189 (NS) \\
Anti Smith & $6(30 \%)$ & $11(27.5 \%)$ & 0.041 & $0.839(\mathrm{NS})$ \\
Anti-nucleosome & $7(35 \%)$ & $19(47.5 \%)$ & 0.849 & 0.357 (NS) \\
Anti Ro-52 & $5(25 \%)$ & $5(12.5 \%)$ & 1.500 & $0.278(\mathrm{NS})$ \\
Anti Ro-60 & $5(25 \%)$ & $9(22.5 \%)$ & 0.047 & $1.000(\mathrm{NS})$ \\
Anti La & $1(5 \%)$ & 0 & 2.034 & $0.333(\mathrm{NS})$ \\
Anti CENP & $1(5 \%)$ & 0 & 2.034 & $0.333(\mathrm{NS})$ \\
Anti histone & $2(10 \%)$ & $4(10 \%)$ & 0.000 & $1.000(\mathrm{NS})$ \\
Anti Sm-RNP & $5(25 \%)$ & $11(27.5 \%)$ & 0.043 & $1.000(\mathrm{NS})$ \\
Anti ribosome & $1(5 \%)$ & $1(2.5 \%)$ & 0.259 & $1.000(\mathrm{NS})$ \\
Anti U1-RNB & $2(10 \%)$ & $8(20 \%)$ & 0.960 & $0.471(\mathrm{NS})$ \\
Anti Jo-1 & 0 & $1(2.5 \%)$ & 0.508 & $1.000(\mathrm{NS})$ \\
Anti PCNA & 0 & $1(2.5 \%)$ & 0.508 & $1.000(\mathrm{NS})$ \\
Anti SCL-100 & 0 & $2(5 \%)$ & 1.034 & $0.548(\mathrm{NS})$ \\
Anti Ku & 0 & $2(5 \%)$ & 1.034 & $0.548(\mathrm{NS})$ \\
\hline
\end{tabular}

The group of lymphopenia showed significantly more liability to develop complement deficiency (both C3 and C4). Other elements of the 2019 ACR/EULAR classification criteria for SLE showed non-significant differences between the two groups (Table 4). 
Table (4): 2019 ACR/EULAR criteria for SLE among both groups

\begin{tabular}{|c|c|c|c|c|c|}
\hline & \multicolumn{2}{|c|}{ Lymphopenia } & \multirow[t]{2}{*}{ Chi square } & \multirow[t]{2}{*}{$P$ value } \\
\hline & & Positive $(n=20)$ & Negative $(n=40)$ & & \\
\hline Fever & & $14(70 \%)$ & $23(57.5 \%)$ & 0.881 & $0.348(\mathrm{NS})$ \\
\hline \multirow[t]{4}{*}{ Mucocutaneous } & Alopecia & 0 & $1(2.5 \%)$ & 0.508 & $1.000(\mathrm{NS})$ \\
\hline & Oral ulcers & $14(70 \%)$ & $25(62.5 \%)$ & 0.330 & $0.566(\mathrm{NS})$ \\
\hline & Subacute cut. lupus & 0 & 0 & - & - \\
\hline & Acute cut. lupus & $1(5 \%)$ & $4(10 \%)$ & 0.436 & $0.656(\mathrm{NS})$ \\
\hline Musculoskeletal & Arthritis & $10(50 \%)$ & $17(42.5 \%)$ & 0.303 & $0.582(\mathrm{NS})$ \\
\hline \multirow[t]{3}{*}{ Neurological } & Delirium & 0 & 0 & - & - \\
\hline & Psychosis & $2(10 \%)$ & $3(7.5 \%)$ & 0.109 & $1.000(\mathrm{NS})$ \\
\hline & Seizures & $1(5 \%)$ & $1(2.5 \%)$ & 0.259 & $1.000(\mathrm{NS})$ \\
\hline \multirow[t]{2}{*}{ Serositis } & $\begin{array}{l}\text { Pleural or } \\
\text { pericardial effusion }\end{array}$ & $1(5 \%)$ & $5(12.5 \%)$ & 0.833 & $0.653(\mathrm{NS})$ \\
\hline & Pericarditis & 0 & 0 & - & - \\
\hline \multirow[t]{3}{*}{ Hematological } & Leucopenia & $4(20 \%)$ & $10(25 \%)$ & 0.186 & $0.756(\mathrm{NS})$ \\
\hline & $\begin{array}{l}\text { Thrombo- } \\
\text { cytopenia }\end{array}$ & $7(35 \%)$ & $4(10 \%)$ & 5.566 & $0.031(S)$ \\
\hline & Hemolytic anemia & 0 & $2(5 \%)$ & 1.034 & $0.548(\mathrm{NS})$ \\
\hline \multirow[t]{3}{*}{ Renal } & Isolated proteinuria & 0 & $1(2.5 \%)$ & 0.508 & $1.000(\mathrm{NS})$ \\
\hline & Class II or V LN & $3(15 \%)$ & $8(20 \%)$ & 0.233 & $0.736(\mathrm{NS})$ \\
\hline & Class III or IV LN & $1(5 \%)$ & $4(10 \%)$ & 0.436 & $0.656(\mathrm{NS})$ \\
\hline Anti-phospholipid & APS & $1(5 \%)$ & $4(10 \%)$ & 0.436 & $0.656(\mathrm{NS})$ \\
\hline \multirow[t]{2}{*}{ Complement } & C3 or C4 & $2(10 \%)$ & $7(17.5 \%)$ & 0.588 & $0.443(\mathrm{NS})$ \\
\hline & $\mathrm{C} 3$ and $\mathrm{C} 4$ & $5(25 \%)$ & $1(2.5 \%)$ & 7.500 & $0.013(\mathrm{~S})$ \\
\hline \multirow[t]{2}{*}{ Specific SLE antibodies } & Anti ds- DNA & $10(50 \%)$ & $27(67.5 \%)$ & 1.727 & $0.189(\mathrm{NS})$ \\
\hline & Anti Smith & $6(30 \%)$ & $11(27.5 \%)$ & 0.041 & $0.839(\mathrm{NS})$ \\
\hline
\end{tabular}

The mean total score of the 2019 ACR/EULAR criteria in the lymphopenic group was $15.60 \pm 5.91$, while in nonlymphopenic group was $15.88 \pm 4.54$, with no significant difference between the two groups $(\mathrm{P}$ value $=0.842)$.

The lymphopenia group showed significantly more hypochromic anemia with significant lower hemoglobin level and lower mean corpuscular volume (MCV). The mean creatinine level was significantly higher among lymphopenic cases compared to those with normal lymphocytic count. The P/C ratio was higher among cases with lymphopenic cases compared to those with normal lymphocytic count, but with a non-significant difference (Table 5).

Table (5): Laboratory investigations in the study groups

\begin{tabular}{|c|c|c|c|c|c|}
\hline & Lymphopenia & Mean & Std. Deviation & T test & P value \\
\hline \multirow[t]{2}{*}{ WBCs $\left(\times 10^{3} / \mathrm{ul}\right)$} & Positive & 7.367 & 1.937 & 0.657 & 0.514 \\
\hline & Negative & 6.521 & 1.908 & & (NS) \\
\hline \multirow[t]{2}{*}{ Lymphocytes \% } & Positive & $15.04 \%$ & $3.41 \%$ & 9.319 & $<0.001$ \\
\hline & Negative & $41.78 \%$ & $9.43 \%$ & & (HS) \\
\hline \multirow[t]{2}{*}{ HB $(\mathrm{g} / \mathrm{dl})$} & Positive & 9.125 & 1.614 & 3.020 & $0.004(\mathrm{~S})$ \\
\hline & Negative & 10.521 & 1.713 & & \\
\hline \multirow[t]{2}{*}{ MCV (fL) } & Positive & 72.685 & 8.411 & 3.028 & $0.004(\mathrm{~S})$ \\
\hline & Negative & 79.411 & 7.843 & & \\
\hline \multirow[t]{2}{*}{ PLT $\left(x 10^{3} / \mathrm{ul}\right)$} & Positive & 218.710 & 8.233 & 1.693 & $0.096(\mathrm{NS})$ \\
\hline & Negative & 264.821 & 17.912 & & \\
\hline \multirow[t]{2}{*}{$\operatorname{ESR}(\mathrm{mm} / \mathrm{hr})}$. & Positive & 70.63 & 8.092 & 1.008 & 0.318 \\
\hline & Negative & 62.03 & 3.261 & & \\
\hline \multirow[t]{2}{*}{ ALT (U/L) } & Positive & 22.90 & 5.106 & $336^{*}$ & 0.386 \\
\hline & Negative & 24.59 & 5.323 & & \\
\hline \multirow[t]{2}{*}{$\operatorname{AST}(\mathrm{U} / \mathrm{L})$} & Positive & 36.05 & 8.368 & $289 *$ & 0.105 \\
\hline & Negative & 24.56 & 6.885 & & \\
\hline \multirow[t]{2}{*}{ Creatinine $(\mathrm{mg} / \mathrm{dl})$} & Positive & 1.142 & 0.080 & 2.717 & $0.009(\mathrm{~S})$ \\
\hline & Negative & 0.766 & 0.153 & & \\
\hline \multirow[t]{2}{*}{ Protein/creat ratio } & Positive & 1.236 & 0.14 & 0.265 & $0.792(\mathrm{NS})$ \\
\hline & Negative & 1.104 & 0.17 & & \\
\hline
\end{tabular}

* Mann Whitney test was used instead of $\mathrm{t}$ test due to non parametric data-Lymphopenic cases had higher proteinuria compared to cases with normal lymphocytic count, with a significant difference $(\mathrm{P}=0.002)$ (Figure 2). 


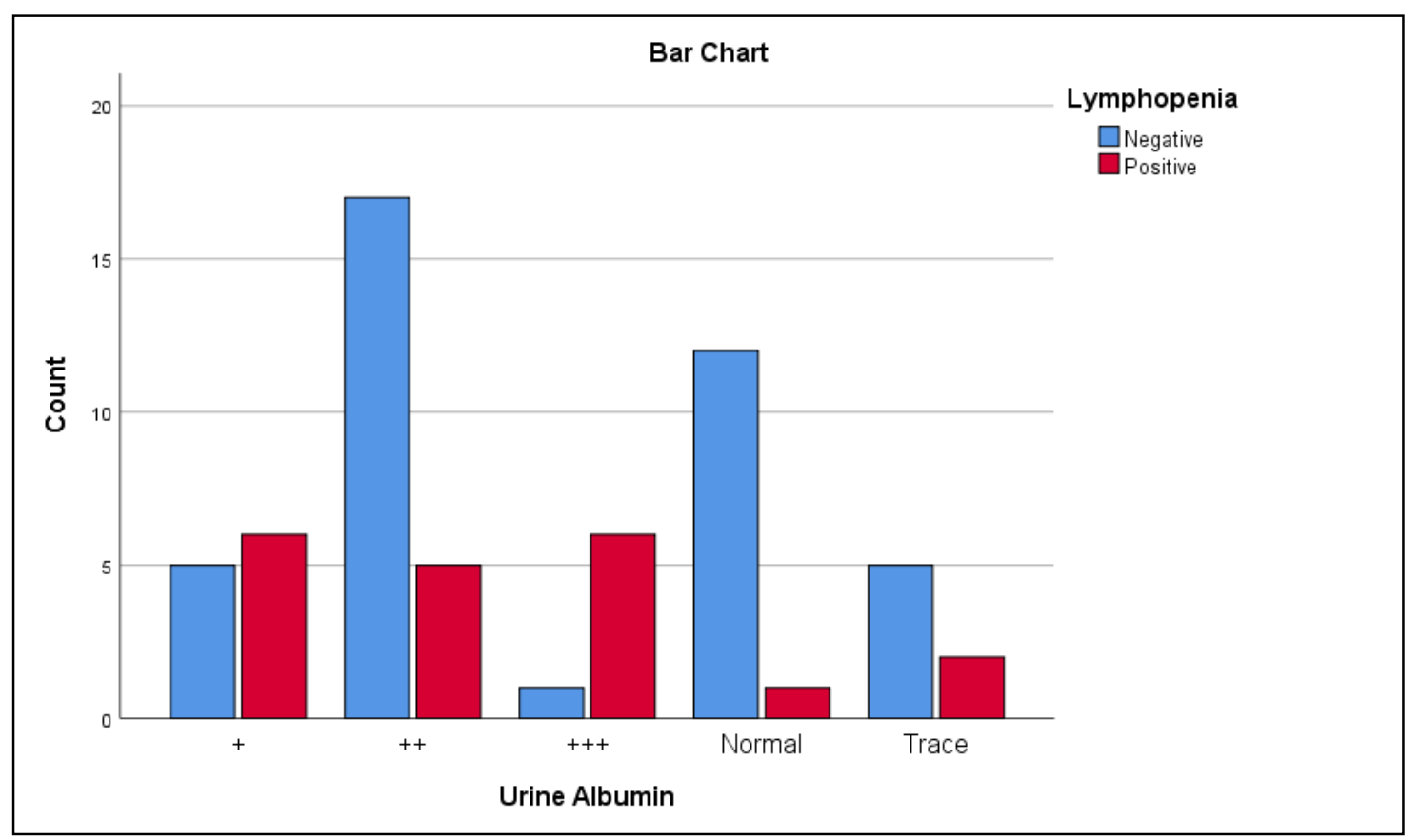

Figure (2): Urine albumin in the study groups

\section{DISCUSSION}

SLE is characterized by a wide variety of clinical and laboratory presentations affecting almost all organ systems and may results in severe organ or lifethreatening manifestations ${ }^{(7)}$.

Lymphopenia is a common clinical manifestation of SLE and is one of the hematological criteria according to the 1997-ACR classification criteria of SLE ${ }^{(8)}$. Lymphopenia has been reported in up to $90 \%$ of SLE patients along their disease course ${ }^{(4)}$.

Two thirds of this study population had normal lymphocytic count, and one third had lymphopenia which is lower than study of Sonhy et al. ${ }^{(9)}$ as lymphopenia was found in $46 \%$ of the their patients. Moreover, Rivero et al. ${ }^{(\mathbf{1 0})}$ found a higher frequency of $78 \%$.

The mean age of this study population was around 32-33 years, with no significant difference between the two groups. All of the cases were females. In our study, the mean disease duration of the study groups were 4 years for cases with lymphopenia compared to 3.6 years for those with normal lymphocytic count, with no significant difference.

In this study, there was non-significant difference between lymphopenia groups as regards azathioprine, cyclophosphamide and hydroxychloroquine therapy. However, cases with normal lymphocytic count received significantly higher doses of steroids compared to those with lymphopenia and only 3 cases needed mycophenolate mofetil treatment.

Also, in study of Faddah et al. ${ }^{(11)}$, there were no statistically significant differences in drug intake including hydroxychloroquine, azathioprine, cyclophosphamide (IV pulse) and mycophenolate mofetil between lymphopenic and non-lymphopenic patients which is similar to present study. On the other hand, Yu et al. (4) found that lymphopenia was significantly related to pulse steroid therapy (methyl prednisolone $1 \mathrm{gm}$ daily for 3-5 days) taken during lupus flares. Furthermore, Vilá et al. ${ }^{(6)}$ found that lymphopenia was associated with both corticosteroids and azathioprine intake but not with hydroxychloroquine or pulse IV cyclophosphamide.

The majority of our cases had ANA titres between $1 / 80$ to $1 / 320$, with no significant difference between the two groups regarding ANA titre, homogenous pattern was the dominant pattern among lymphopenic cases, opposite to those with normal lymphocytic count, where the dominant pattern was the speckled one. However, the difference was non significant. The most common ANA antibodies were the anti dsDNA, anti-Smith, anti nucleosome, anti SmRNB; followed by anti Ro and Anti La. All these antibodies showed non significant differences between the two groups. In line with our results, Faddah $\boldsymbol{e t}$ al. (11) found in their study that there were no significant differences between autoantibodies viz ANAs, antidsDNA, aCL (IgG and IgM) among lymphopenic and non-lymphopenic patients. In contrast, Vilá et al. ${ }^{(6)}$ stated that lymphopenia was positively associated with anti-dsDNA antibodies but not with ANA or aCL. Also, Yu et al. ${ }^{(4)}$ found that lymphopenia was significantly associated with anti-dsDNA antibodies. The explanation here may be the possible lymphocytotoxic activity of anti-dsDNA antibodies through crossreactivity between nuclear antigen and lymphocyte membrane ${ }^{(\mathbf{1 2})}$. Contrarily, other authors didn't find any significant association with anti-ds DNA ${ }^{(4,11)}$. This is in line with the present results.

Thrombocytopenia was significantly more common among cases with lymphopenia. The complement system is an essential part of the innate immunity system ${ }^{(\mathbf{1 3})}$, as it plays an important role in the 
removal of atypical antigens and immune complex ${ }^{(14)}$. In SLE, hypocomplementemia is an important serological marker of ongoing inflammation where complement elements are "consumed" by tissue bound immune complexes ${ }^{(\mathbf{1 5})}$. In spite of some few exceptions, a strong correlation was suggested between SLE disease activity especially renal flare and drop in complement levels (what is called $\mathrm{C} 3$ and $\mathrm{C} 4$ consumption) ${ }^{(\mathbf{1 6}, 17)}$. Taking in consideration the association of lymphopenia with disease activity in the current study, the association between lymphopenia and consumed C 3 is an expected result. This is supported by Sobhy et al. ${ }^{(9)}$ and a previous study of Yu et al. ${ }^{(4)}$ while on the other hand, others found no link ${ }^{(11)}$.

In the current study, the lymphopenia group showed significantly more hypochromic anemia with significant lower hemoglobin level and lower MCV, the mean creatinine level was significantly higher among lymphopenic cases compared to those with normal lymphocytic count. Lymphopenic cases had higher proteinuria compared to cases with normal lymphocytic count, with a significant difference. The $\mathrm{P} / \mathrm{C}$ ratio was higher among cases with lymphopenic cases compared to those with normal lymphocytic count, but with a nonsignificant difference. However, the results of Faddah et al. (11) showed that lymphopenia was significantly associated with leucopenia but not with hemolytic anemia or thrombocytopenia. In accordance to our study, Vilá et al. ${ }^{(4)}$ and Yu et al. ${ }^{(6)}$ both found that lymphopenia was associated with leucopenia.

In this study, the total score of the 2019 ACR/EULAR criteria had similar means between the two groups, with no significant difference. There was non-significant difference between the two groups regarding classes of lupus nephritis. The total number of biopsy-diagnosed lupus nephritis was limited in our study, and this may explain the non-significant difference between the two groups.

We found that the mean activity score of SLE was slightly higher among cases with lymphopenia compared to those with normal lymphocytic count, with non-significant difference. Similar to our study, Sobhy et $\boldsymbol{a l} .{ }^{(\boldsymbol{9})}$ and Vilá et $\boldsymbol{a l} .{ }^{\left({ }^{(6)}\right.}$ found that the SLEDAI was higher in the lymphopenic SLE group compared to non lymphopenic SLE one, although their results did not reach the statistical significance threshold. On the other hand, Faddah et al. (11) reported that there was a statistically significant association between lymphopenia and disease activity which was also the results of both Yu et al. ${ }^{(4)}$ and Mirzayan et al. ${ }^{(18)}$. This may be explained by the fact that in active SLE, lymphocytes may undergo apoptosis resulting from activation induced cell death through Fas and Fas ligand pathway ${ }^{(19,20)}$ or death by neglect-apoptosis pathway (21). Also, CD4+ and CD8+ T-cells that bear the CD28 molecule may decrease in the peripheral blood of SLE patients. CD28 mediated costimulation influences Tcell susceptibility to activation induced cell death and may be involved in T-cell lymphopenia ${ }^{(\mathbf{1 9})}$. Also, anti-
CD4 antibodies are frequently found in patients with SLE $^{\text {(22). }}$.

\section{CONCLUSIONS}

It could be concluded that lymphopenia in patients with SLE may be useful in prediction of internal organ involvement. Lymphopenia was associated with more hypochromic anemia with significant lower hemoglobin level and lower MCV, higher creatinine level, and higher proteinuria. The $\mathrm{P} / \mathrm{C}$ ratio was higher among cases with lymphopenic cases compared to those with normal lymphocytic count, but with a nonsignificant difference.

Financial support and sponsorship: Nil. Conflict of interest: Nil.

\section{REFERENCES}

1. Yeh T, Yang Y, Lin Y et al. (2007): Cardiopulmonary involvement in pediatric systemic lupus erythematosus: a twenty-year retrospective analysis. J Microbiol Immunol Infect., 40(6):525-31.

2. Merayo-Chalico J, Gomez-Martin D, PineiruaMenendez A et al. (2013): Lymphopenia as risk factor for development of severe infections in patients with systemic lupus erythematosus: a case-control study. An International Journal of Medicine, 106(5):451-7.

3. Ng W, Chu C, Wu A et al. (2006): Lymphopenia at presentation is associated with increased risk of infections in patients with systemic lupus erythematosus. QJM., 99(1):37-47.

4. Yu H, Wang L, Lee J et al. (2007): Lymphopenia is associated with neuropsychiatric manifestations and disease activity in paediatric systemic lupus erythematosus patients. Rheumatology, 46(9):1492-4.

5. Castelino D, McNair P, Kay T (1997): Lymphocytopenia in a hospital population-what does it signify?. Australian and New Zealand Journal of Medicine, 27(2):170-4.

6. Vilá L, Alarcón G, McGwin J et al. (2006): Systemic lupus erythematosus in a multiethnic US cohort, XXXVII: association of lymphopenia with clinical manifestations, serologic abnormalities, disease activity, and damage accrual. Arthritis Care \& Research: Official Journal of the American College of Rheumatology, 55(5):799-806.

7. Rabbani M, Siddiqui B, Tahir M et al. (2006): Do clinical manifestations of Systemic Lupus Erythematosus in Pakistan correlate with rest of Asia? Journal of Pakistan Medical Association, 56(5):222-26.

8. Hochberg M (1997): Updating the American College of Rheumatology revised criteria for the classification of systemic lupus erythematosus. Arthritis Rheum., 40(9):1725-29.

9. Sobhy N, Niazy M, Kamal A (2020): Lymphopenia in systemic lupus erythematosus patients: Is it more than a laboratory finding? The Egyptian Rheumatologist, 42(1):23-6.

10. Rivero S, Díaz-Jouanen E, Alarcón-Segovia D (1978): Lymphopenia in systemic lupus erythematosus. Arthritis \& Rheumatism: Official Journal of the American College of Rheumatology, 21(3):295-305. 
11. Faddah S, Elwakd M, Aboelenein A et al. (2014): Lymphopenia and systemic lupus erythematosus, a preliminary study: Correlation with clinical manifestations, disease activity and damage indices. The Egyptian Rheumatologist, 36(3):125-30.

12. Shoenfeld Y, Zamir R, Joshua H et al. (1985): Human monoclonal anti-DNA antibodies react as lymphocytotoxic antibodies. European Journal of Immunology, 15(10):1024-8.

13. Bao L, Cunningham P, Quigg R (2015): Complement in lupus nephritis: new perspectives. Kidney Diseases, 1(2):91-9.

14. Pettigrew H, Teuber S, Gershwin M (2009): Clinical significance of complement deficiencies. Annals of the New York Academy of Sciences, 1173(1):108-23.

15. Raymond W, Eilertsen G, Nossent J (2018): Hypocomplementemia as a risk factor for organ damage Accrual in patients with systemic lupus erythematosus. https://www.hindawi.com/journals/jir/2018/8051972/

16. Narayanan $K$, Marwaha V, Shanmuganandan $K$ et al. (2010): Correlation between systemic lupus erythematosus disease activity index, C3, C4 and antidsDNA antibodies. Medical Journal Armed Forces India, 66(2):102-7.
17. Ho A, Barr S, Magder L et al. (2001): A decrease in complement is associated with increased renal and hematologic activity in patients with systemic lupus erythematosus. Arthritis \& Rheumatism, 44(10):2350-7.

18. Mirzayan M, Schmidt R, Witte T (2000): Prognostic parameters for flare in systemic lupus erythematosus. Rheumatology, 39(12):1316-9.

19. Kaneko H, Saito K, Hashimoto $H$ et al. (1996): Preferential elimination of CD28+ T cells in systemic lupus erythematosus (SLE) and the relation with activation-induced apoptosis. Clinical \& Experimental Immunology, 106(2):218-29.

20. Silvestris F, Grinello D, Tucci M et al. (2003): Enhancement of $\mathrm{T}$ cell apoptosis correlates with increased serum levels of soluble Fas (CD95/Apo-I) in active lupus. Lupus, 12(1):8-14.

21. Silva L, Garcia A, Donadi E (2002): Increased lymphocyte death by neglect-apoptosis is associated with lymphopenia and autoantibodies in lupus patients presenting with neuropsychiatric manifestations. Journal of Neurology, 249(8):1048-54.

22. Lenert P, Lenert G, Senecal J (1996): CD4-reactive antibodies in systemic lupus erythematosus. Hum Immunol., 49(1):38-48. 